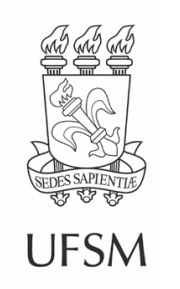

\title{
Artigos
}

\section{Retenção de água em substratos com hidrogel: influência das características do material e nível de adubação}

\author{
Water retention in hydrogel substrates: influence of the material \\ characteristics and the fertilizing level
}

\author{
Orlando Sílvio Caires Neves ${ }^{1}$ \\ Eduarda Demari Avrella" $\odot$ \\ Luciana Pinto Paim" ${ }^{\odot}$ \\ Claudimar Sidnei Fior ${ }^{\prime \prime}$
}

'Universidade Federal da Bahia, Vitória da Conquista, BA, Brasil

"Universidade Federal do Rio Grande do Sul, Porto Alegre, RS, Brasil

\section{RESUMO}

Considerando-se que os substratos apresentam constituições físico-químicas diversas e que a liberação de íons do substrato, ou a adição de fertilizantes, eleva a condutividade elétrica da solução, este trabalho teve como objetivo avaliar a retenção de água em substratos com hidrogel com presença e ausência de adubação. O delineamento experimental utilizado foi o inteiramente casualizado, em esquema fatorial $4 \times 3 \times 2$, com quatro repetições. Os fatores constituíram de quatro tipos de substratos (casca de pinus compostada, pó-de-coco (fibra do mesocarpo triturada), turfa de Sphagnum e substrato comercial (à base de turfa de Sphagnum, vermiculita expandida, casca de arroz torrefada, calcário dolomítico e gesso agrícola), três formas de aplicação do produto hidrogel (sem aplicação, com aplicação sem pré-hidratação e com aplicação após hidratação) e duas formas de aplicação de fertilização de base (na presença e ausência). O hidrogel utilizado foi um copolímero de poliacrilato de potássio $\left(\mathrm{K}_{2} \mathrm{~S}_{2} \mathrm{O}_{8}\right)$. Os resultados apontam que a adição de hidrogel promove melhorias na capacidade de retenção de água dos substratos, contudo, é influenciada pela sua composição e pela presença de fertilizantes químicos. Quanto maior a Condutividade Elétrica (CE) do substrato, menor é o potencial de hidratação do hidrogel. A forma de aplicação do hidrogel, se seco ou pré-hidratado, não influencia a capacidade de retenção de água pelos substratos. O hidrogel aplicado no substrato, uma vez desidratado, mantém sua capacidade de reidratação.

Palavras-chave: Hidrorretentor; Condutividade elétrica; Fertilização 


\section{ABSTRACT}

Considering that the substrates have different physical and chemical constitutions and that the release of ions from the substrate or the addition of fertilizers increases the electrical conductivity of the solution, the objective of this work was to evaluate the water retention in substrates with hydrogel, without and with fertilization. The experimental design used was a completely randomized, in a $4 \times 3$ $\times 2$ factorial scheme, with four replications. The factors consisted of four substrates (composted pine bark, coconut powder (crushed mesocarp fiber), Sphagnum peat and commercial substrate (based on Sphagnum peat, expanded vermiculite, roasted rice husk, dolomitic limestone and plaster), three forms of application of the hydrogel product (without application, with application without pre-hydration and with application after hydration) and two ways of applying the basic fertilization (present and absent) .The hydrogel used was a potassium polyacrylate copolymer $\left(\mathrm{K}_{2} \mathrm{~S}_{2} \mathrm{O}_{8}\right)$. The results show that the addition of hydrogel promotes improvements in the water retention capacity of the substrates However, it is influenced by its composition and by the presence of chemical fertilizers. The higher the EC of the substrate, the lower the hydration potential of the hydrogel. The hydrogel application method, whether dry or pre-hydrated, does not influence the water retention capacity by the substrates. The hydrogel applied to the substrate once dehydrated, maintains its ability to rehydrate.

Keywords: Electric conductivity; Fertilization; Water retainer

\section{INTRODUÇÃO}

Substrato para plantas é todo material poroso, usado puro ou em mistura, que, colocado em um recipiente, proporciona ancoragem e suficientes níveis de água e oxigênio para um ótimo desenvolvimento das plantas (VENCE, 2008). Cada substrato tem composição química específica e influencia diretamente a condutividade elétrica (CE). Por exemplo, a turfa Sphagnum tem uma baixa CE, enquanto a casca de pinus compostada e a fibra de coco, geralmente, apresentam CE ligeiramente superior (CAVINS et al., 2000).

A CE é um parâmetro simples e de baixo custo para sua determinação (MOTA et al., 2013), sendo uma medida de resistência à passagem da corrente elétrica entre os eletrodos submetidos à uma solução, onde solutos iônicos (cátions e ânions) estão presentes. Quanto maior a concentração de sais dissolvidos, maior será o valor da CE, sendo, portanto, uma medida indireta da concentração iônica da solução (SCHMITT et al., 2016). 
Para Navroski et al. (2016b), a fertilização é uma das práticas mais importantes na produção de mudas, especialmente quando as plantas são produzidas em recipientes, os quais limitam o seu crescimento. A eficiência das adubações depende basicamente das doses e fontes dos adubos utilizados e da capacidade de troca catiônica do substrato. Muito se discute sobre a potencialização do efeito das adubações pelo uso do hidrogel, mas Gervásio e Frizone (2004) observaram que quando polímeros hidrorretentores são incorporados aos substratos de cultivo, os resultados são variados nas respostas às características de retenção, consumo de água e crescimento das plantas. Segundo esses autores, os copolímeros frequentemente utilizados apresentam elevada capacidade de absorção em água destilada, entretanto são fisicamente instáveis na presença de sais devido às poucas e fracas ligações cruzadas.

O copolímero de poliacrilato de potássio é uma molécula com grande capacidade para a absorção de água, devido à sua particular conformação, dada pela presença de sais de potássio. Em contato com a água, os grupos carboxílicos do polímero dissociam-se em íons carboxílicos de carga negativa. Esse processo causa um enriquecimento de cadeias moleculares com grupos iônicos de carga igual, com a tendência de repelirem entre si. Como resultado, há um aumento do volume da cavidade do polímero, consequentemente maior armazenamento de água. A natureza do arranjo das moléculas confere a esse material uma forma granular quando seco e, ao ser hidratado, os grânulos se dilatam, transformando-se em partículas de gel (PREVEDELLO; BALENA, 2000).

De forma geral, as conclusões sobre a utilização do hidrogel são amplas e não consideram as características químicas da solução ou do substrato a ser utilizado. Como exemplo, Navroski et al. (2016a) relatam que o hidrogel adicionado ao substrato auxilia na retenção de água, melhorando os atributos que envolvem armazenamento e disponibilidade de água para as plantas, mas esses autores não diferenciam as condições químicas do meio ou da solução. 
Considerando-se que os substratos apresentam constituições físico-químicas diversas e que a liberação de íons do substrato, ou a adição de fertilizantes, eleva a condutividade elétrica da solução, este trabalho teve como objetivo avaliar a retenção de água em substratos com hidrogel, com e sem adubação, de forma a testar a hipótese de que a eficiência do hidrogel é prejudicada em determinadas características do material e da condição química do substrato.

\section{MATERIAL E MÉTODOS}

O experimento foi conduzido em casa de vegetação do Departamento de Horticultura e Silvicultura, da Faculdade de Agronomia da Universidade Federal do Rio Grande do Sul (UFRGS), em Porto Alegre/RS, no período de junho a novembro de 2019.

O delineamento experimental utilizado foi o inteiramente casualizado, em esquema fatorial $4 \times 3 \times 2$, com quatro repetições. Os fatores se constituíram de quatro substratos (casca de pinus compostada, pó-de-coco (fibra do mesocarpo triturada e peneirada em malha de $5 \mathrm{~mm}$ ), turfa de Sphagnum e substrato comercial (à base de turfa de Sphagnum, vermiculita expandida, casca de arroz torrefada, calcário dolomítico e gesso agrícola), três formas de aplicação do produto hidrogel (sem aplicação, com aplicação sem pré-hidratação e com aplicação após hidratação) e duas formas de aplicação de fertilização de base (na presença e ausência). Dentre os atributos físicos relacionados, a densidade úmida (DU) e a densidade seca (DS) foram avaliadas pelo método de auto compactação (HOFFMANN, 1970). A porosidade total (PT), o espaço de aeração (EA), a água remanescente (AR) e a água disponível (AD) foram avaliadas no Laboratório de Substratos da Faculdade de Agronomia da UFRGS, a 0, 10, 50 e 100 hPa, usando funis de tensão de acordo com os princípios de De Boodt e Verdonck (1972). As características físico-químicas dos substratos estão apresentadas na Tabela 01. 
Tabela 1 - Caracterização das propriedades dos substratos

\begin{tabular}{ccccc}
\hline \multirow{2}{*}{ Propriedades } & \multicolumn{4}{c}{ Substratos } \\
\cline { 2 - 5 } & $\begin{array}{c}\text { Turfa de } \\
\text { Sphagnum }\end{array}$ & $\begin{array}{c}\text { Casca de pinus } \\
\text { compostada }\end{array}$ & Comercial & Pó-de-coco \\
\hline DU $\left(\mathrm{kg} \mathrm{m}^{-3}\right)$ & 395,60 & 674,32 & 256,29 & 356,5 \\
DS $\left(\mathrm{kg} \mathrm{m}^{-3}\right)$ & 98,22 & 448,09 & 142,75 & 87,71 \\
UA (\%) & 75,17 & 33,55 & 43,20 & 75,96 \\
PT (\%) & 99,48 & 79,27 & 77,07 & 91,81 \\
EA (\%) & 32,39 & 32,09 & 31,15 & 29,65 \\
AD (\%) & 36,27 & 19,83 & 15,92 & 32,97 \\
AR (\%) & 30,82 & 27,35 & 30,00 & 29,19 \\
$*$ *E (mS cm-1) & 0,32 & 2,04 & 1,02 & 0,38 \\
${ }^{*}$ pH (H2O) & 4,50 & 6,40 & 6,40 & 6,30 \\
\hline
\end{tabular}

Fonte: Autores (2020)

Em que: $\mathrm{DU}$ = densidade úmida; $\mathrm{DS}$ = densidade seca; $\mathrm{UA}=$ umidade atual; $\mathrm{PT}$ = porosidade total; $\mathrm{EA}=$ espaço de aeração; $\mathrm{AD}$ = água disponível; $\mathrm{AR}$ = água remanescente; $\mathrm{CE}=$ condutividade elétrica; $\mathrm{pH}$ = potencial hidrogeniônico; *Método de Extração PourThru.

$\mathrm{O}$ hidrogel utilizado foi um copolímero de poliacrilato de potássio $\left(\mathrm{K}_{2} \mathrm{~S}_{2} \mathrm{O}_{8}\right)$, insolúvel em água, apresentando tamanho de partículas que variam de 0,1 a 0,9 mm. Apresenta densidade em massa de 580 a $800 \mathrm{~g} \mathrm{~L}^{-1}$, capacidade de troca catiônica de $3.100 \mathrm{mmol} \mathrm{dm}^{-3}$ e capacidade de absorção de água de, aproximadamente, 210 vezes a sua massa seca.

A formulação para a adubação foi baseada nas recomendações para plantas em substratos, adaptada de Penningsfeld (1983), na qual foram diluídos 2,5 g do produto comercial Kristalon $^{\circledR}$ e 1,25 g de nitrato de cálcio em um litro de água, e aplicados 35 $\mathrm{mL}$ diretamente no substrato, para cada tratamento. De acordo com informações do fabricante, o fertilizante Kristalon $^{\circledR}$ contém $6 \%$ de N (4,5\% em forma nítrica e 1,5\% amoniacal), $12 \% \mathrm{P}_{2} \mathrm{O}_{5^{\prime}}, 36 \% \mathrm{~K}_{2} \mathrm{O}, 1,8 \% \mathrm{Mg}$, 8\% de $\mathrm{S}, 0,07 \% \mathrm{Fe}, 0,025 \% \mathrm{~B}, 0,01 \% \mathrm{Cu}, 0,04 \%$ Mn, $0,004 \%$ Mo e $0,025 \%$ de Zn.

A parcela experimental foi composta por um recipiente que continha um orifício de 10 mm de diâmetro na parte basal e estava apoiado sobre pratos plásticos. Os substratos foram conduzidos para a secagem em estufa a $65^{\circ} \mathrm{C}$, até peso constante. 
Após secos, $700 \mathrm{~mL}$ de cada substrato foram acondicionados em vasos (na ausência de plantas) com capacidade para I L, cujas respectivas massas foram: 95,00 g para a turfa de Sphagnum; 368,30 g para a casca de pinus compostada; 121,40 g para o substrato comercial e 80,10 g para o pó-de-coco.

Duas horas após a pesagem dos substratos, procedeu-se a mistura dos fertilizantes e do hidrogel (dose equivalente a $4 \mathrm{~g} \mathrm{~L}^{-1}$ de substrato), para os tratamentos que previam tal aplicação e, em seguida, o material foi transferido para os recipientes. Para o tratamento com o hidrogel pré-hidratado, este foi posto para intumescimento em água deionizada, por duas horas, e misturado ao substrato.

Todos os tratamentos foram umedecidos com água deionizada adicionada sobre o substrato e por capilaridade a partir da base dos vasos (água adicionada nos pratos), para os dois ciclos de umedecimento. Duas horas após atingir a capacidade de vaso (ponto máximo de umedecimento), realizou-se a primeira pesagem para a determinação da retenção de água em cada tratamento, que consistiu na diferença entre o peso final do substrato hidratado e seu peso inicial (seco), descontando-se o peso do recipiente. Os resultados obtidos para os tratamentos foram expressos em: g de $\mathrm{H}_{2} \mathrm{O}$ retida por $\mathrm{kg}$ de substrato e g de $\mathrm{H}_{2} \mathrm{O}$ retida por $\mathrm{L}$ de substrato. A partir da primeira pesagem, no primeiro ciclo de hidratação, novas pesagens foram realizadas a cada sete dias, até o último substrato (tratamento que não recebeu o hidrogel) ter atingido o percentual de água remanescente obtido na análise (Tabela 1).

Os substratos foram submetidos a um segundo ciclo de umedecimento (reidratação), também com água deionizada, até atingirem novamente a capacidade de vaso. Com tais medidas, foi possível traçar o comportamento de secagem de cada substrato, considerando-se os tratamentos, e avaliar a contribuição do copolímero na umidade "residual" do substrato.

As medidas de $\mathrm{pH}$ e a condutividade elétrica (CE) dos substratos foram realizadas através da leitura direta do lixiviado, conforme o Método PourThru (CAVINS et al., 2000). 
Os dados obtidos foram submetidos à análise de variância e, quando significativa, aplicou-se o teste Tukey, a 5\% de probabilidade de erro, para a comparação das médias. Para os dados de CE e pH do lixiviado, relacionados com o potencial de retenção de água dos substratos, aplicou-se a correlação de Pearson. Para todas as análises descritas foi utilizado o programa estatístico SISVAR, versão 5.7 (FERREIRA, 2018).

\section{RESULTADOS E DISCUSSÃO}

A correlação entre a CE e a umidade dos substratos utilizados, determinada no ponto de capacidade de vaso e influenciada pela hidratação do hidrogel aplicado (Figura 1A), foi significativa e negativa, independentemente se no primeiro ciclo $(r=$ $-0,92 ; p \leq 0,01)$ ou no segundo ciclo de hidratação $(r=-0,92 ; p \leq 0,01)$. O comportamento revela que a capacidade de hidratação do hidrogel é influenciada negativamente pela condutividade elétrica do substrato. $\mathrm{O}$ pH do substrato não se correlacionou com a umidade (Figura 1B), independentemente do ciclo de hidratação, evidenciando que este não interfere na capacidade de hidratação do hidrogel.

Bortolin et al. (2012) verificaram que a capacidade de hidratação do hidrogel reduziu drasticamente quando o meio de intumescimento foi variado de água destilada para solução contendo íons. Quando o hidrogel é imerso em uma solução contendo íons, podem ocorrer interações localizadas entre os grupamentos hidroxila com os contra-íons do sal, o que pode induzir a formação de pares iônicos (ou complexos iônicos). Consequentemente, possíveis repulsões eletrostáticas entre os segmentos das cadeias são minimizadas, dificultando as expansões localizadas das redes dos hidrogéis (BORTOLIN et al., 2016). Coadunando com Bortolin et al. (2012), e considerando-se que a CE é uma medida indireta da concentração iônica, os resultados

obtidos no presente estudo evidenciaram que o potencial de intumescimento do hidrogel foi menor para os substratos com maior CE. 
Figura 1 - Correlação entre a condutividade elétrica (CE) e a umidade dos substratos (\%), no ponto de capacidade de vaso (dois ciclos de hidratação), sem e com aplicação de $4 \mathrm{~g} \mathrm{~L}^{-1}$ de hidrogel (A); correlação entre o pH e a umidade dos substratos (\%), na capacidade de vaso (dois ciclos de hidratação), sem e com aplicação de $4 \mathrm{~g} \mathrm{~L}^{-1}$ de hidrogel (B). ** Correlação de Pearson, significativa 1\% de probabilidade de erro. ${ }^{\text {ns }}$ Não significativa

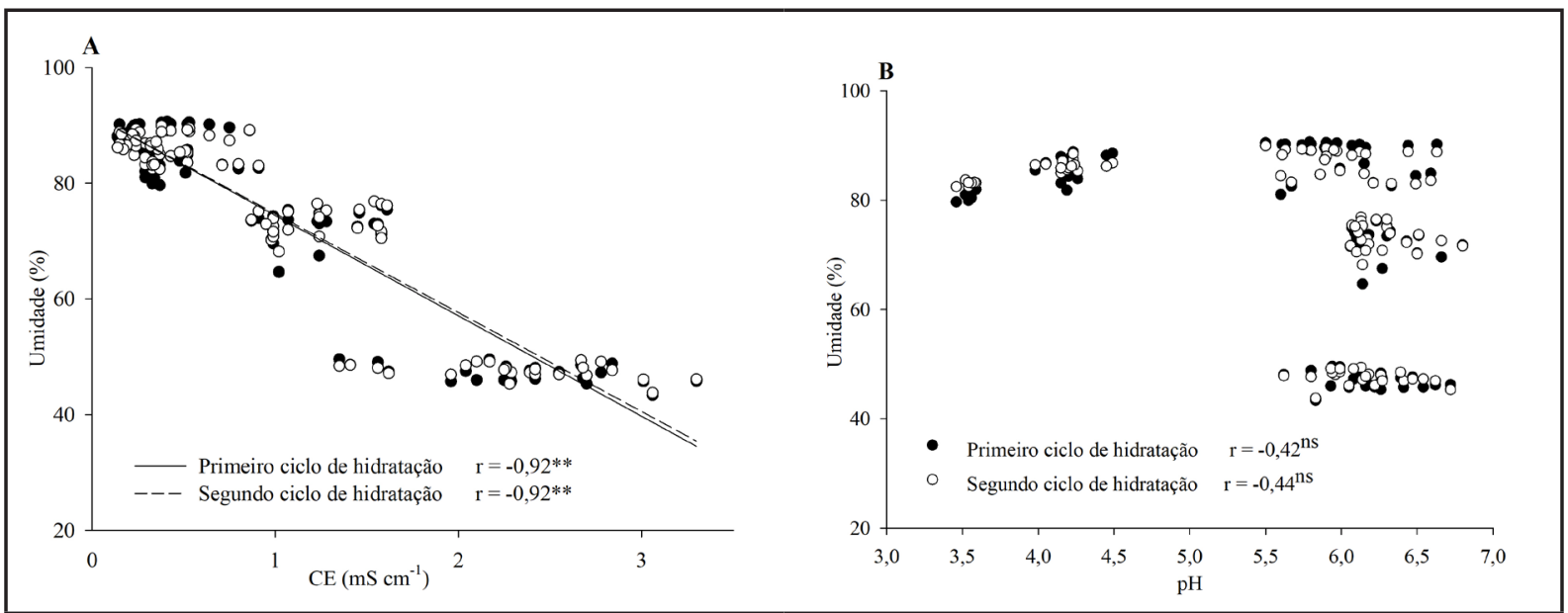

Fonte: Autores (2020)

Para os dados obtidos neste estudo, a partir dos diferentes substratos, a análise de variância realizada para a variável umidade, expressa em percentagem, tanto para o primeiro ciclo (CV = 1,89\%) quanto para o segundo ciclo (CV = 1,55\%) de hidratação, revelou que a interação tripla "tipos de substratos x com ou sem a aplicação de fertilização de base x formas de aplicação do hidrogel" e a interação dupla "com ou sem a aplicação de fertilização de base x formas de aplicação do hidrogel" não foram significativas ao nível de $1 \%$ de probabilidade de erro (p 0,08 e 0,72, respectivamente, para o primeiro ciclo e p 0,54 e 0,13, respectivamente, para o segundo ciclo). Entretanto, as interações duplas "tipos de substratos x com ou sem a aplicação de fertilização de base" e "tipos de substratos $x$ formas de aplicação do hidrogel" foram significativas e os resultados estão apresentados nas Tabelas 2 e 3. 
Tabela 2 - Desdobramento do efeito da adição ou não da fertilização de base sobre a umidade (\%), dentro e entre cada tipo de substrato, determinada no ponto de capacidade de vaso

\begin{tabular}{lcccc}
\hline & \multicolumn{4}{c}{ Substratos } \\
\cline { 2 - 5 } & $\begin{array}{c}\text { Casca de pinus } \\
\text { compostada }\end{array}$ & Comercial & $\begin{array}{c}\text { Turfa de } \\
\text { Sphagnum }\end{array}$ & Pó-de-coco \\
\hline Primeiro ciclo de hidratação & & & & \\
Sem fertilização de base & $47,59 \mathrm{Da}$ & $73,00 \mathrm{Ca}$ & $83,38 \mathrm{Bb}$ & $86,65 \mathrm{Aa}$ \\
Com fertilização de base & $46,53 \mathrm{Da}$ & $72,14 \mathrm{Ca}$ & $85,34 \mathrm{Ba}$ & $87,67 \mathrm{Aa}$ \\
& & & & \\
Segundo ciclo de hidratação & & & $85,07 \mathrm{Ba}$ & $87,47 \mathrm{Aa}$ \\
Sem fertilização de base & $47,73 \mathrm{Da}$ & $74,17 \mathrm{Ca}$ & $86,89 \mathrm{Aa}$ \\
Com fertilização de base & $47,33 \mathrm{Ca}$ & $72,48 \mathrm{Bb}$ & $85,69 \mathrm{Aa}$ & 86, \\
\hline
\end{tabular}

Fonte: Autores (2020)

Em que: Médias seguidas da mesma letra maiúscula na linha, dentro de cada ciclo de hidratação, não diferem entre si $(p>0,05)$ pelo teste Tukey; Médias seguidas da mesma letra minúscula na coluna, dentro de cada ciclo de hidratação, não diferem entre si $(p>0,05)$ pelo teste Tukey.

A adubação utilizada neste experimento não afetou a capacidade de hidratação do hidrogel misturado aos substratos casca de pinus e pó-de-coco, independentemente do ciclo de hidratação estudado. Entretanto, a capacidade de hidratação do hidrogel, inferida pela unidade do substrato, foi influenciada positivamente pela fertilização no primeiro ciclo de hidratação no substrato turfa de Sphagnum e negativamente no segundo ciclo de hidratação, para o substrato comercial. Cabe destacar que a CE da turfa de Sphagnum $\left(0,32 \mathrm{mS} \mathrm{cm}^{-1}\right)$ foi a menor entre os substratos estudados, seguida pelo pó-de-coco $\left(0,38 \mathrm{mS} \mathrm{cm}^{-1}\right)$, substrato comercial $\left(1,02 \mathrm{mS} \mathrm{cm}^{-1}\right)$ e casca de pinus $\left(2,04 \mathrm{mS} \mathrm{cm}^{-1}\right)$.

Tanto no primeiro quanto no segundo ciclo de hidratação e independentemente da aplicação ou não da adubação de base, verifica-se (Tabela 2) que a máxima capacidade de reter água, determinada no ponto de capacidade de vaso e expressa em termos de umidade (\%), difere significativamente entre os substratos, sendo da maior para menor, na seguinte ordem: pó-de-coco > turfa de Sphagnum > substrato comercial > casca de pinus. 
A aplicação de hidrogel nos substratos pó-de-coco, turfa de Sphagnum e comercial influenciou positivamente no teor de água desses, não importando se a incorporação é realizada com o produto seco ou pré-hidratado, mas não tem efeito sobre o substrato casca de pinus (Tabela 3). O mesmo comportamento foi verificado nos dois ciclos de hidratação do substrato, que ocorreu num intervalo de 112 dias. Fica evidenciado, também, que o hidrogel aplicado no substrato, uma vez desidratado, mantém sua capacidade de reidratação. Vale ressaltar que, neste experimento, só foram avaliados os dois primeiros ciclos de hidratação.

Tabela 3 - Desdobramento do efeito da aplicação do hidrogel sobre a umidade (\%), dentro e entre cada tipo de substrato, determinada no ponto de capacidade de vaso

\begin{tabular}{lcccc}
\hline & \multicolumn{4}{c}{ Substratos } \\
\cline { 2 - 5 } & $\begin{array}{l}\text { Casca de pinus } \\
\text { compostada }\end{array}$ & Comercial & $\begin{array}{c}\text { Turfa de } \\
\text { Sphagnum }\end{array}$ & Pó-de-coco \\
\hline Primeiro ciclo de hidratação & $46,13 \mathrm{Da}$ & $70,17 \mathrm{Cb}$ & $80,86 \mathrm{Bb}$ & $84,38 \mathrm{Ab}$ \\
$\begin{array}{l}\text { Sem hidrogel } \\
\text { Com hidrogel aplicado seco }\end{array}$ & $47,05 \mathrm{Da}$ & $73,66 \mathrm{Ca}$ & $85,60 \mathrm{Ba}$ & $90,17 \mathrm{Aa}$ \\
$\begin{array}{l}\text { Com hidrogel aplicado pré- } \\
\text { hidratado }\end{array}$ & $48,15 \mathrm{Da}$ & $73,90 \mathrm{Ca}$ & $86,25 \mathrm{Ba}$ & $89,25 \mathrm{Aa}$ \\
& & & & \\
$\begin{array}{l}\text { Segundo ciclo de hidratação } \\
\text { Sem hidrogel }\end{array}$ & $47,22 \mathrm{Ca}$ & $71,33 \mathrm{Bb}$ & $83,24 \mathrm{Ab}$ & $83,87 \mathrm{Ab}$ \\
$\begin{array}{l}\text { Com hidrogel aplicado seco } \\
\text { Com hidrogel aplicado pré- }\end{array}$ & $46,95 \mathrm{Da}$ & $74,62 \mathrm{Ca}$ & $86,43 \mathrm{Ba}$ & $88,93 \mathrm{Aa}$ \\
hidratado & $48,01 \mathrm{Da}$ & $74,01 \mathrm{Ca}$ & $86,48 \mathrm{Ba}$ & $88,74 \mathrm{Aa}$ \\
\hline
\end{tabular}

Fonte: Autores (2020)

Em que: Médias seguidas da mesma letra maiúscula na linha, dentro de cada ciclo de hidratação, não diferem entre si $(p>0,05)$ pelo teste Tukey; Médias seguidas da mesma letra minúscula na coluna, dentro de cada ciclo de hidratação, não diferem entre si $(p>0,05)$ pelo teste Tukey.

A não significância na elevação da capacidade de retenção de água no substrato em função da presença do hidrogel em casca de pinus, possivelmente, está relacionada à concentração de íons livres, que foi aferida neste estudo através CE deste substrato $\left(2,04 \mathrm{mS} \mathrm{cm}^{-1}\right)$. Neves et al. (2020) concluíram que a capacidade de hidratação do hidrogel diminui com a elevação da condutividade elétrica na solução. 
Estudos visando a redução na lâmina e a frequência da irrigação na produção de mudas de espécies utilizadas na agricultura e silvicultura, aliando substratos com polímeros hidrorretentores sintéticos, são cada vez mais frequentes (SAAD; LOPES; SANTOS, 2009). O hidrogel, que tem o potencial para absorver 150 a 400 vezes sua massa seca, pode ser utilizado para aumentar a capacidade de armazenamento de água do substrato minimizando os problemas associados à disponibilidade irregular e deficitária de água (MARQUES; CRIPA; MARTIZEZ, 2013). Verifica-se, entretanto, pelos resultados obtidos neste estudo, que o efeito positivo na retenção de água pelo substrato, proporcionado pela aplicação do hidrogel, não é uma regra, sendo a CE do substrato um parâmetro importante a ser considerado e mais estudado.

A literatura retrata que o elevado potencial de absorção dos polímeros, quando submetidos à saturação em água, não é o mesmo quando são misturados em meios de cultivo, seja solo ou substrato. Gervásio e Frizone (2004) concluíram que a expansão dos polímeros hidroabsorventes fica limitada na presença de solução salina. Já Bowman et al. (1990) constataram que a intensidade de redução na absorção está relacionada à valência dos íons presentes na solução, sendo que a absorção é mais afetada na presença de cátions bivalentes, sendo, pois, improvável que a adição de hidrogéis aumente de maneira significativa a capacidade de retenção de água em substratos, principalmente em sistemas de produção intensivos de mudas, nos quais os níveis de adubação utilizados são elevados.

Os resultados destes experimentos apontaram para a significância do hidrogel quando aplicado aos substratos na elevação do teor de água, exceto para a casca de pinus; entretanto, em regimes de cultivo com adubações constantes e em doses elevadas, o que pode elevar a CE do substrato, o efeito poderá ser nulo. Para os tratamentos nos quais o hidrogel foi misturado seco, a contribuição deste na elevação da umidade do substrato foi de apenas 3,5, 4,7 e 5,8\%, respectivamente, para os substratos comercial, turfa de Sphagnum e pó-de-coco. Quando a aplicação do hidrogel foi realizada com o produto previamente hidratado, a contribuição foi de 3,7, 5,4 e 4,9\%, respectivamente, para os substratos comercial, turfa de Sphagnum e pó-de-coco. 
Resultados de algumas pesquisas têm mostrado o efeito benéfico da utilização destes polímeros hidrorretentores incorporados ao substrato para a produção de mudas de algumas espécies (MOREIRA et al., 2010; BERNARDI et al., 2012; MARQUES; CRIPA; MARTIZEZ, 2013; NAVROSKI et al., 2015). Durante o processo de hidratação, elementos nutrientes de plantas são liberados do hidrogel para a solução, destacadamente o potássio. Se não for considerada a especificidade do substrato utilizado, parte dos "efeitos benéficos" pode ser atribuída ao componente nutrição e, outra parte, à melhoria da capacidade na retenção de água. Os diferentes substratos estudados apresentam comportamentos distintos quando submetidos à aplicação de hidrogel, sendo variáveis ou mesmo nulas suas respostas para a melhoria na capacidade de aumentar a retenção de água.

Tatagiba et al. (2019), em um estudo que objetivou avaliar a disponibilidade hídrica e doses de polímero hidrorretentor na produção de mudas clonais de eucalipto, utilizando um substrato composto por 30\% de fibra de coco, 35\% de vermiculita e 35\% de casca de arroz carbonizada, acrescidos de $2,0 \mathrm{~kg} \mathrm{~m}^{-3}$ de fertilizante de liberação lenta (10-03-09) e 2,0 $\mathrm{kg} \mathrm{m}^{-3}$ de superfosfato simples (18\% de $\mathrm{P}_{2} \mathrm{O}_{5}$ ), testaram doses de hidrogel e reduções na lâmina de irrigação de 0, 30 e 50\%. Esses autores verificaram que a umidade do substrato, independentemente da aplicação ou não do hidrogel, não diferiu de forma significativa entre os tratamentos, entretanto, não informaram os dados sobre a CE do substrato utilizado.

Na Figura 2, estão representadas as curvas temporais de desidratação dos substratos casca de pinus compostada; comercial; pó-de-coco e turfa de Sphagnum, em ambiente protegido, sem controle das condições de temperatura e umidade relativa do ar.

O último substrato a atingir o nível de água remanescente foi a turfa de Sphagnum (Figura 2D), na qual o tratamento sem a aplicação de hidrogel, utilizado como parâmetro para determinar o fim das avaliações, atingiu 30\% de umidade aos 112 dias. Para todos os substratos estudados, os tratamentos sem a aplicação de 
hidrogel, com ou sem aplicação de adubação de base, apresentaram comportamentos semelhantes quanto ao ritmo de desidratação.

Figura 2 - Curvas de desidratação dos substratos ao longo do tempo, conforme os tratamentos, formas de aplicação do hidrogel e da adubação de base. Substrato casca de pinus compostada (A); substrato comercial (B); substrato pó-de-coco (C); e substrato turfa de Sphagnum (D)

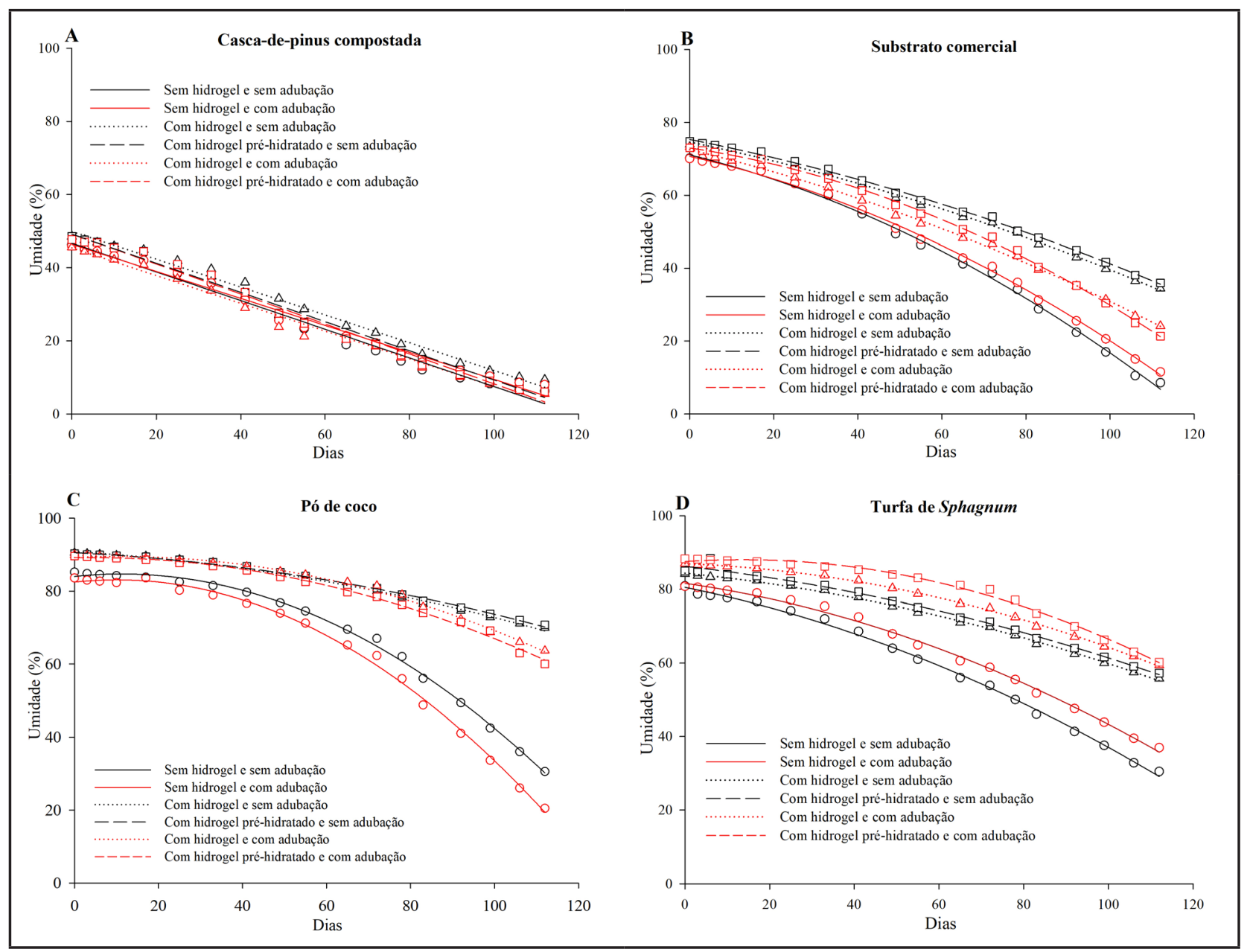

Fonte: Autores (2020)

Para o substrato casca de pinus (Figura 2A), todos os tratamentos, independentemente da adição ou não do hidrogel e da adubação de base, apresentaram o mesmo comportamento linear e proporcional de desidratação, chegando ao fim do experimento com a umidade por volta de $10 \%$.

Os tratamentos com a adição de hidrogel nos substratos comercial (Figura 
2B), pó-de-coco (Figura 2C) e turfa de Sphagnum (Figura 2D) apresentaram um menor ritmo de desidratação quando comparados aos tratamentos em que não se aplicou o hidrogel, sendo que o efeito ficou mais pronunciado com o tempo de condução do experimento. Esse comportamento foi mais pronunciado para o substrato pó-decoco, onde a umidade aos 112 dias dos tratamentos sem hidrogel foi por volta de $20 \%$. Já os tratamentos com a adição de hidrogel ainda apresentavam cerca de 60\%.

O hidrogel adicionado ao substrato auxilia na retenção de água, melhorando os atributos que envolvem armazenamento e disponibilidade de água às plantas (NAVROSKI et al., 2016a). Prevedello e Loyola (2007) afirmaram que, além da habilidade de armazenar e disponibilizar água às plantas, quando necessário, o hidrogel ainda pode agir como agente tamponante contra o estresse hídrico temporário. Neste estudo, esse comportamento pode ser observado, sobretudo quando os substratos utilizados foram o pó-de-coco e a turfa de Sphagnum, mas o mesmo não aconteceu para a casca de pinus.

De maneira prática, pode-se inferir que, embora o incremento em retenção de água (em capacidade de vaso) proporcionado pela presença do hidrogel seja baixo, o principal efeito do polímero fica evidente na conservação dessa água ao longo do período entre irrigações. Essa pode ser uma importante estratégia para evitar a desidratação excessiva de mudas em períodos de maior demanda hídrica, favorecendo a padronização do stand em viveiros. Por outro lado, é importante frisar que, de acordo com a condição química resultante da mistura dos materiais usados como substrato, a incorporação do hidrogel não apresenta efeito na retenção de água. Isso também pode ocorrer em cultivos, cujo manejo preveja a aplicação de elevadas doses de fertilizantes em adubação de base. Portanto, não é possível afirmar que o uso do hidrogel em substrato seja vantajoso na manutenção da umidade junto às raízes das plantas, sem que seja considerado o material e/ou o nível de adubação utilizado. 


\section{CONCLUSÕES}

A adição de hidrogel promove melhorias na capacidade de retenção de água dos substratos, contudo, é influenciada pela sua composição e pela presença de fertilizantes químicos. Quanto maior a CE do substrato, menor é o potencial de hidratação do hidrogel.

A forma de aplicação do hidrogel, se seco ou pré-hidratado, não influencia a capacidade de retenção de água pelos substratos.

O hidrogel aplicado no substrato, uma vez desidratado, mantém sua capacidade de reidratação.

\section{REFERÊNCIAS}

BERNARDI, M. R. et al. Crescimento de mudas de Corymbia citriodora em função do uso de hidrogel e adubação. Cerne, Lavras, v. 18, n. 1, p. 67-74, 2012.

BORTOLIN, A. etal. Investigação do processo de absorção de água de hidrogéis de polissacarídeo: efeito da carga iônica, presença de sais, concentrações de monômero e polissacarídeo. Polímeros, São Carlos, v. 22, n. 4, p. 311-317, ago. 2012.

BORTOLIN, A. et al. Macro- and Micronutrient Simultaneous Slow Release from Highly Swellable Nanocomposite Hydrogels. Journal Agricultural Food Chemistry, [s. I.], v. 64, n. 16, p. 31333140, 2016.

BOWMAN, D. C. et al. Fertilizer salts reduce hydration of polyacrylamide gels and affect physical properties of gel-amended container media. Journal of the American Society for Horticultural Science, Alexandria, v. 115, n. 3, p. 382-386, 1990.

CAVINS, T. J. et al. Monitoring and managing $\mathrm{pH}$ and EC using the PourThru extraction method. Horticulture Information Leaflet, [s. I.], v. 7, p. 1-17, 2000.

DE BOODT, M.; VERDONCK, O. The physical properties of the substrates in horticulture. Acta Horticulturae, Wageningen, n. 26, p. 37-44, 1972.

FERREIRA, D. F. Programa computacional Sisvar-UFLA, versão 5.7. [S. I.: s. n.], 2018.

GERVÁSIO, E. S.; FRIZZONE, J. A. Caracterização físico-hídrica de um condicionador de solo e seus efeitos quando misturado a um substrato orgânico. Irriga, Botucatu, v. 9, n. 2, p. 94-105, maio/ago. 2004.

HOFFMANN, G. Verbindliche methoden zur untersuchungvom TKS und gartnerischen erden. Mitteilungen der VSLUFA, Heft, v. 6, p. 129-156, 1970. 
MARQUES, P. A. A; CRIPA, M. A. M.; MARTIZEZ, E. H. Hidrogel como substituto da irrigação complementar em viveiro telado de mudas de cafeeiro. Ciência Rural, Santa Maria, v. 43, n. 1, p. 1-7, jan. 2013.

MOTA, P. R. D. et al. Condutividade elétrica da solução nutritiva e acúmulo de macro e micronutrientes no cultivo de crisântemo. Bragantia, Campinas, v. 72. n. 1, p. 81-89, 2013.

MOREIRA, R. A. et al. Efeito de doses de polímero hidroabsorvente no enraizamento de estacas de amoreira. Revista Agrarian, [s. I.], v. 3, n. 8, p. 133-139, 2010.

NAVROSKI, M. C. et al. Influência do hidrogel no crescimento e no teor de nutrientes das mudas de Eucalyptus dunnii. Floresta, Curitiba, v. 45, p. 315-328, 2015.

NAVROSKI, M. C. et al. Influência do polímero hidroretentor nas características do substrato comercial para produção de mudas florestais. Interciência, Caracas, v. 41, n. 5, p. 357-361, 2016a. Disponível em: http://www.redalyc.org/articulo.oa?id=33945552012. Acesso em: 05 fev. 2021.

NAVROSKI M. C. et al. Redução da adubação e melhoria das características do substrato com o uso do hidrogel na produção de mudas de Eucalyptus dunnii maiden. Ciência Florestal, Santa Maria, v. 26, n. 4, p. 1155-1165, out./dez. 2016b. DOI: 10.5902/1980509825106

NEVES, O. S. C. et al. Influence of nitrates, phosphate, sulfate and salts of $\mathrm{Ca}, \mathrm{Mg}$ and $\mathrm{K}$, on hydrogel hydrtation capacity. Revista Árvore, Viçosa, MG, v. 44, e4408, 2020. DOI: 10.159/1806908820200000008

PENNINGSFELD, F. Plant substrates for horticulture with special regard to Germany: a critical review. Plant and Soil, The Hague, v. 75, n. 3, p. 269-281, 1983.

PREVEDELLO, C. L.; BALENA, S. P. Efeitos de polímeros hidrorretentores nas propriedades físico-hídricas de dois meios porosos. Revista Brasileira de Ciência do Solo, Viçosa, MG, v. 24, n. 2, p. 251-258, 2000.

PREVEDELLO, C. L.; LOYOLA, J. M. T. Efeito de polímeros hidroretentores na infiltração da água no solo. Scientia Agraria, Curitiba, v. 8, n. 3, p. 313-317, 2007.

SAAD, J. C. C.; LOPES, J. L. W.; SANTOS, T. A. Manejo hídrico em viveiro e uso de hidrogel na sobrevivência pós-plantio de Eucalyptus urograndis em dois solos diferentes. Engenharia Agrícola, Jaboticabal, v. 29, n. 3, p. 404-411, jul./set. 2009.

SCHMITT, O. J. et al. P. Produção de estolhos de cultivares de morangueiro em função da condutividade elétrica da solução nutritiva. Horticultura Brasileira, Vitoria da Conquista, v. 34, n. 2, p. 294-301, abr./jun. 2016.

TATAGIBA, S. D. et al. Disponibilidade hídrica e doses de polímero hidrorretentor na produção de mudas clonais de eucalipto. Revista Engenharia na Agricultura, Viçosa, MG, v. 27, n. 4, p. 359-369, 2019. DOI: https://doi.org/10.13083/reveng.v27i4.938.

VENCE, L. B. Disponibilidad de agua-aire en sustratos para plantas. Ciencia del Suelo, La Plata, v. 26, n. 2, p. 105-114, 2008. 


\section{Contribuição de Autoria}

\section{1 - Orlando Sílvio Caires Neves}

Engenheiro Agrônomo, Dr., Professor

https://orcid.org/0000-0002-8723-4840•orlandosilvio@ufba.br

Contribuição: Conceituação, Curadoria de dados, Análise Formal, Investigação, Metodologia, Software, Visualização de dados, Escrita - primeira redação, Escrita revisão e edição

\section{2 - Eduarda Demari Avrella}

Engenheira Florestal, Doutora em Fitotecnia

https://orcid.org/0000-0002-8819-983X·dudademari@hotmail.com

Contribuição: Conceituação, Metodologia, Escrita - revisão e edição

\section{3 - Luciana Pinto Paim}

Engenheira Agrônoma, Doutora em Fitotecnia https://orcid.org/0000-0003-0779-6091 • lucianappaim@bol.com.br Contribuição: Conceituação, Metodologia, Escrita - revisão e edição

\section{4 - Claudimar Sidnei Fior}

Engenheiro Agrônomo, Dr., Professor

https://orcid.org/0000-0001-9893-081X·csfior@ufrgs.br

Contribuição: Conceituação, Obtenção de financiamento, Metodologia, Administração do projeto, Escrita - revisão e edição

\section{Como citar este artigo}

Neves, O. S. C.; Avrella, E. D.; Paim, L. P.; Fior, C. S. Retenção de água em substratos com hidrogel: influência das características do material e nível de adubação. Ciência Florestal, Santa Maria, v. 31, n. 4, p. 1751-1767, 2021. DOI 10.5902/1980509843240. Disponível em: https://doi. org/10.5902/1980509843240. 